\title{
Processing, Sintering and Performance of WC-Co-Near-Nano TiC Metal Matrix Composites
}

\author{
Kaçmaz D, Kalkavan F, Yazıcı S, Demirural A and Baykara T* \\ Department of Mechanical Engineering, Dogus University, Turkey \\ *Corresponding author: Baykara T, Department of Mechanical Engineering, Dogus University, Acibadem, Kadikoy, İstanbul, Turkey
}

Submission: January 08, 2019; Published: January 18, 2019

\begin{abstract}
WC-Co base metal matrix composites with the addition of other carbides such as TiC have superior properties such as high hardness, good fracture toughness and high wear resistance. They are typical powder metallurgy products and constitute a complex composite structure with a ductile Co matrix (sometimes Fe and Ni) and extremely hard brittle carbide phase (mostly WC and TiC). Recently, nano and/or near-nano-sized carbide particles are being used to enhance microstructural development to increase hardness and toughness. In this study, the effect of near-nano-sized TiC additions on the microstructural development and densification along with increasing hardness and wear resistance were investigated. Standard WC-13 Co powder mixture was modified with 2 weight \% TiC powders with average of 350-400nm grain size.
\end{abstract}

Keywords: WC-Co metal matrix composites; TiC; Nano-sized TiC; WC-Co-TiC; Near nano-particles

\section{Introduction}

Metal matrix composites, also known as "cemented carbide" and "cermets" in which the base composition consists of WC-Co have been in use since early 1940s and widely applied as cutting and machining tool materials, mining, drilling and tunneling tool bits, forming dies and moulds. They have superior properties such as high hardness, good fracture toughness and high wear resistance. They are typical powder metallurgy products and constitute a complex composite structure with a ductile Co matrix (sometimes $\mathrm{Fe}$ and $\mathrm{Ni}$ ) and extremely hard brittle carbide phase (mostly WC and $\mathrm{TiC}$ ). Addition of other carbide phases such as TiC, TaC, Ti (CN), $\mathrm{NbC}$ in order to improve mechanical properties have been a very well-known process and extensively studied [1,2].

Recently, nano and/or near-nano-sized carbide particles have been used to enhance microstructural development and mechanical properties such as hardness and toughness [1]. Since TiC has excellent properties of high hardness, good hightemperature strength and good corrosion resistance, TiC additions into WC-Co mixture have been widely investigated $[1,3]$. It was reported that $\mathrm{TiC}$ addition up to $20 \%$ increases the hardness of a WC-TiC-Co metal matrix composites [4]. Solid solution formation of mixed carbides of (Ti,W)C due to the diffusion of $\mathrm{W}$ into the TiC lattice is known to improve high temperature strength. Even though the solid solubility of TiC in WC was found to be low, it was reported that $\mathrm{TiC}$ dissolves considerable amount of $\mathrm{WC}$ even at temperatures around $1400{ }^{\circ} \mathrm{C}$ [2]. It should also be noted that the solubility of $\mathrm{TiC}$ in cobalt is about $1.0 \mathrm{wt} \%$ [5]. These results suggest that the formation of a (Ti,W)C solid solution improves the high temperature strength [3]. However, densification behaviour and microstructural development along with other mechanical properties of such a complex composite structure has not been studied extensively. There has been very little research reported on the effect of nano sized TiC additions [2,3].

This study investigated the effect of near-nano-sized $\mathrm{TiC}$ additions on microstructural development and densification along with increasing hardness and wear resistance. Standard, ready-topress WC-13 wt $\%$ Co powder mixture was modified with $2 \mathrm{wt} \% \mathrm{TiC}$ powders with average of 350-400nm grain size. An experimental procedure was applied both to $\mathrm{WC}-13 \mathrm{wt} \%$ ready to press powders and (WC-13 wt $\%$ Co)- WC- 2 wt $\%$ TiC powders using liquid phase sintering cycle in a box furnace with its own atmosphere for the purpose of comparing the effects of TiC addition. The microhardness of the samples was measured along with the microstructural investigation via SEM-EDS techniques. In addition, samples were mounted on cutting tools to machine a medium carbon grade of steel bars to evaluate the material removal performance.

\section{Materials and Methods}

\section{Materials}

Ready-to-press WC-13 wt\% Co powder mixtures (RTP Grade DXS) were purchased from a S. Korean powder manufacturer, the Taegu Tec Company. Average grains size is 1-2 microns. Near-nanosized TiC powders were obtained from a local powder supplier with an average grain size of $350-400 \mathrm{~nm}$. 
Preparation of powder mixtures, forming into green forms

While the WC- $13 \mathrm{wt} \%$ Co is a ready to press powders, $2 \mathrm{wt} \%$ TiC powders are added into the WC-13 wt \% Co and mixed using a turbula mixing machine for $18 \mathrm{hrs}$. Cylindirical "green" samples

\section{Densification}

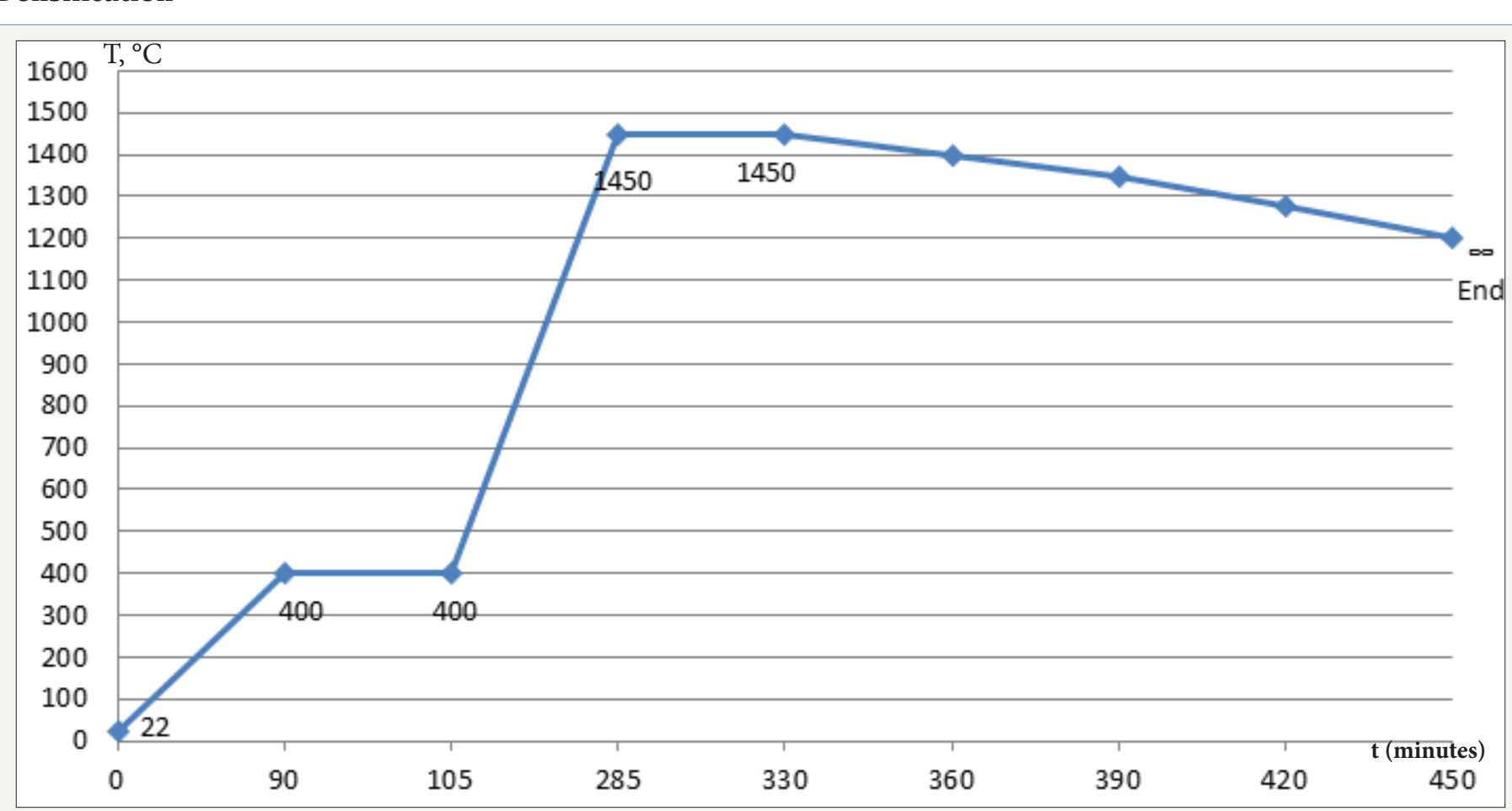

Figure 1: The densification cycle for $\mathrm{WC}-13 \mathrm{wt} \%$ Co grades.

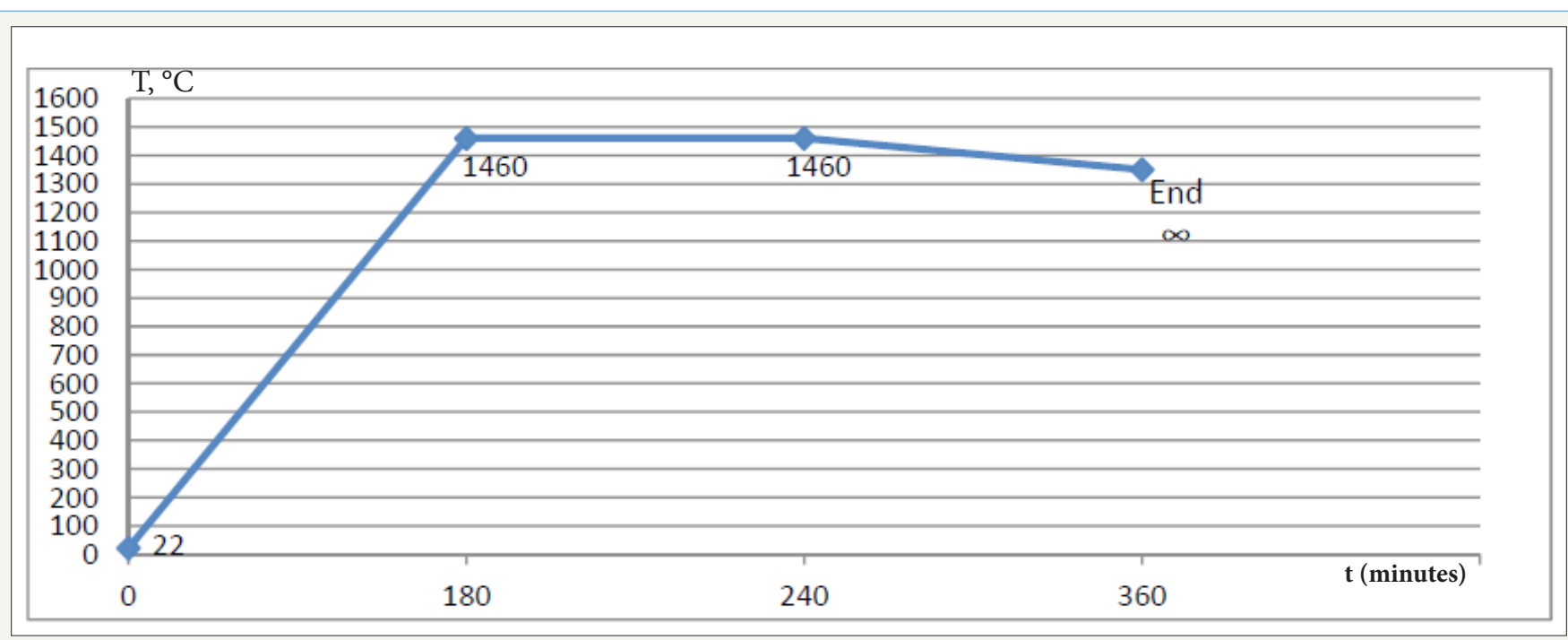

Figure 2: The densification cycle for (WC - 13wt \% Co) $-2 \mathrm{wt} \%$ TiC grades.

Densification of the green samples was achieved in a box type high temperature furnace using the furnace's atmosphere. Samples were also covered with a thick layer of spherical, highly porous carbon particles plus $15 \mathrm{wt} \% \mathrm{Al}_{2} \mathrm{O}_{3}$ mixture to prevent oxidation. of both grades were prepared using a 10 tons mechanical pressing unit under 70-140kg-force $/ \mathrm{cm}^{2}$ pressure. "Green" density was calculated by measuring the weight and volume of the pressed "green" samples. Weight and dimensional measurements indicate the green density for WC-13 wt \% Co as average value of $7.30 \mathrm{~g} / \mathrm{cc}$ and for WC-Co- $2 \mathrm{wt} \% \mathrm{TiC}$ as an average value of $6.72 \mathrm{~g} / \mathrm{cc}$. 
As seen in Figure 1, for the straight WC-Co samples, slow and incremental heating for $280 \mathrm{~min}$ for a complete debinding and $45 \mathrm{~min}$ of sintering at $1450{ }^{\circ} \mathrm{C}$ was applied for the full cycle. Samples were cooled down to room temperature in the furnace atmosphere. Sintered samples are shown in Figure 3.

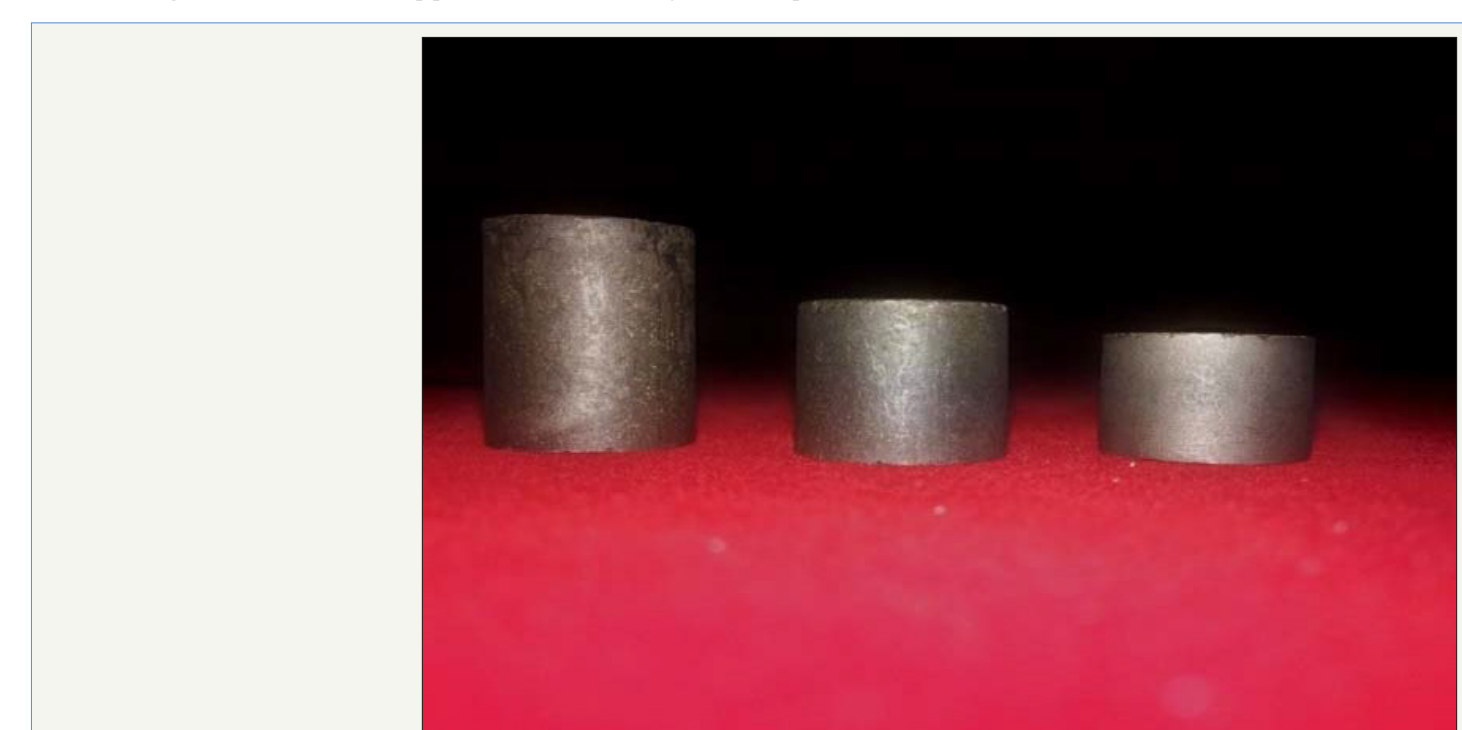

Figure 3: Samples after a densification cycle.

Weight and dimensional measurements indicate the sintered density as an average value of $13.37 \mathrm{~g} / \mathrm{cc}$ revealing that $96.8 \%$ of the theoretical density is achieved. Since, the real measured density is usually $0.5-3 \%$ lower than the theoretical density values due to residual porosities, it is found that $98.3 \%$ of the real density is achieved [6].

As seen in Figure 2 for the TiC added samples, approximately slow heating for $180 \mathrm{~min}$ for a complete debinding and $60 \mathrm{~min}$ of sintering at $1460{ }^{\circ} \mathrm{C}$ was applied for the full cycle. Samples were cooled down to room temperature in the furnace atmosphere.
Sintered samples are shown in Figure 3. Weight and dimensional measurements indicate the sintered density as an average value of $13.19 \mathrm{~g} / \mathrm{cc}$ revealing that approximately $96.9 \%$ of the theoretical density and $98.2 \%$ of the real density is achieved [6].

\section{Microhardness measurements}

Sintered samples were ground and polished for the microhardness measurements using $1 \mathrm{~kg}$ Vickers tip (Figure 4). Total of seven microhardness measurements were completed and tabulated in Table 1.

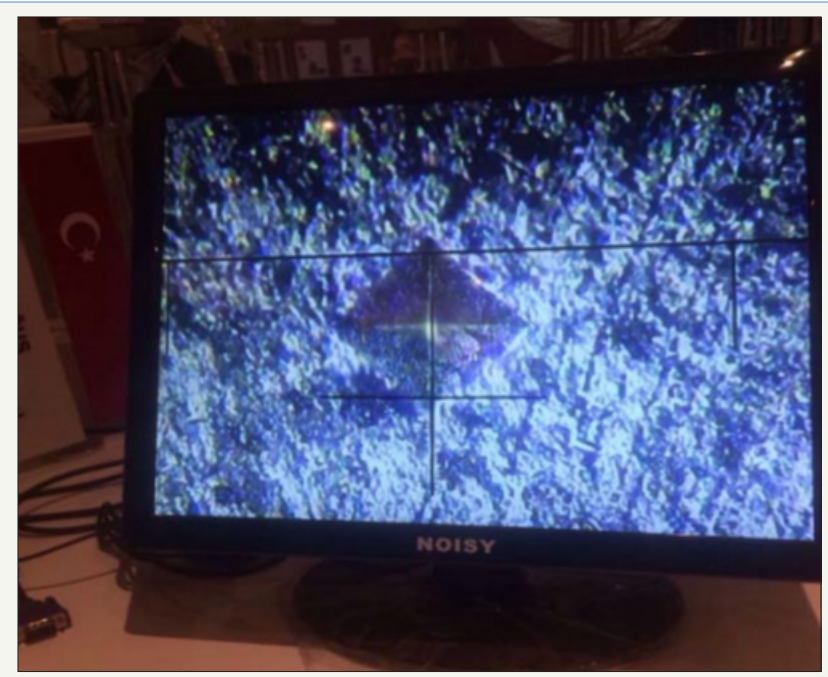

Figure 4: Vickers microhardness measurements.

Table 1: Microhardness measurements using Vickers tip under $1 \mathrm{~kg}$ load.

\begin{tabular}{|c|c|c|}
\hline Measurement No & HV1 data for WC-Co samples & HV1 data for WC-Co-2 wt\% TiC \\
\hline 1 & 1153.3 & 1332.9 \\
\hline 2 & 1087.2 & 1291.1 \\
\hline 3 & 1066.5 & 1257.7 \\
\hline
\end{tabular}




\begin{tabular}{|c|c|c|}
\hline 4 & 1061.4 & 1277.5 \\
\hline 5 & 998.3 & 1392 \\
\hline Average Value & 1073.3 & 1310.2 \\
\hline
\end{tabular}

\section{Microstrucural analysis}

Microstructural analysis was performed using SEM-Scanning Electron Microscopy and EDS techniques on the polished and etched surfaces of the samples. Etching was done using Murakami's agent. Fractured surfaces were also examined. JEOL 6000 Plus desk-top SEM with EDS analysis unit was used. Samples were coated with conductive gold layers before the SEM examinations.

\section{Performance tests}

Cutting tool tips with special angle were prepared from the sintered samples and mounted on the cutting rod via hard soldering. The machining performance of the cutting tool tips were conducted in a turning machine to machine 1050 grade steel bars under identical conditions (rake and cutting angles, feeding and speed) (Figure 5).

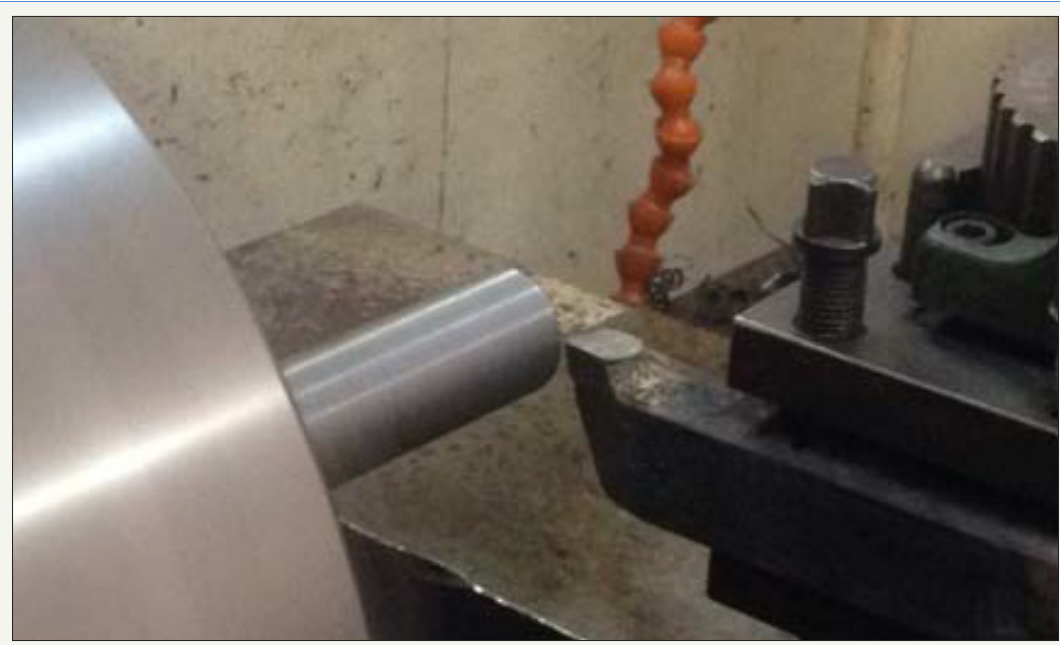

Figure 5: Machining tests using the samples as cutting tools to measure the performance.

\section{Results and Discussion}
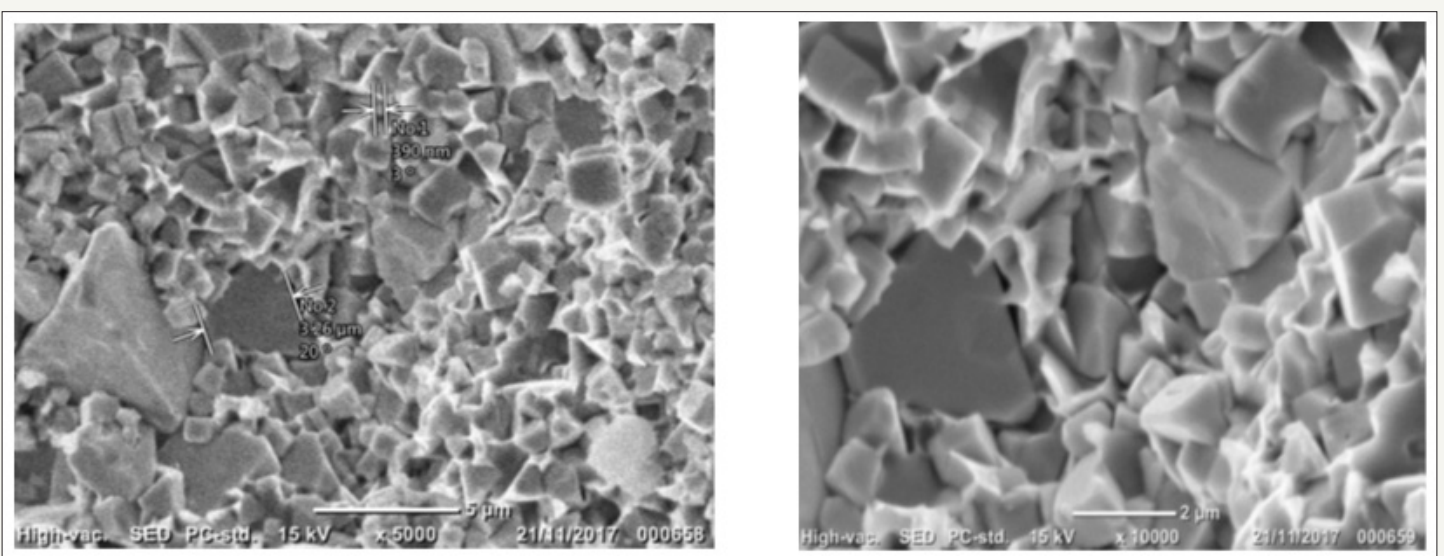

Figure 6: SEM micrographs of the fractured surfaces of WC-13wt\% Co grade (left) x5000 magnification; (right) x10000 magnification.

SEM micrographs in Figure 6 shows the sintered and densified WC- $13 \mathrm{wt} \%$ Co composition with an average grain size of 1-2 micron which reveals typical microstructural features of carbide distribution in a cobalt matrix. Addition of $2 \mathrm{wt} \% \mathrm{TiC}$ with 350 $400 \mathrm{~nm}$ grain size into this composition created a bimodal grain size distribution of WC and TiC in Co matrix.

It has long been claimed that such a bimodal distribution of carbides, WC and TiC in cobalt matrix ensured increased mechanical and wear properties [7]. However, utilization of nano- sized WC and TiC powders leads into the problem of agglomeration during the sintering process and resulted in up to 30-micron sized agglomerates in the microstructure. The tendency for the aglomeration of nano-sized particles during the processing steps (starting with the mixing) is a very well-known problem in the nano-powder processing. In this work, the WC-Co powders were not nano-sized i.e. approximately average 1-2-micron grain size and near-nano sized TiC particles added into the composition using a very well-handled mixing procedure. In the densified 
microstructure, near-nano size TiC is uniformly distributed within the Co matrix and hence reinforce it. Slightly agglomerated TiC particles along the grain boundaries uniformly covered the WC grains and limited the grain growth.

SEM micrographs shown in Figure 7 reveal the microstructure of WC-Co-2 wt\% TiC composition for a flat surface and Figure 8 gives the EDS analysis for the same sample. Figure 9 shows the SEM micrographs for the fractured surface of the same sample with different magnifications. Figure 10 gives the EDS analysis for the same sample. Interconnected angular carbide grains with considerable grain growth can be distinguished in the fractured surface. Very few pores in grain junctions and grown size of average 5-7 micron are the main features of the microstructure. As revealed in Table 1, $20 \%$ increase in the average microhardness value compared to straight WC-Co grade could be attributed to this well packed and coherent structure. It should be noted that the EDS analysis given in Figure 8 \& 10 do not reveal any oxygen in the microstructure.

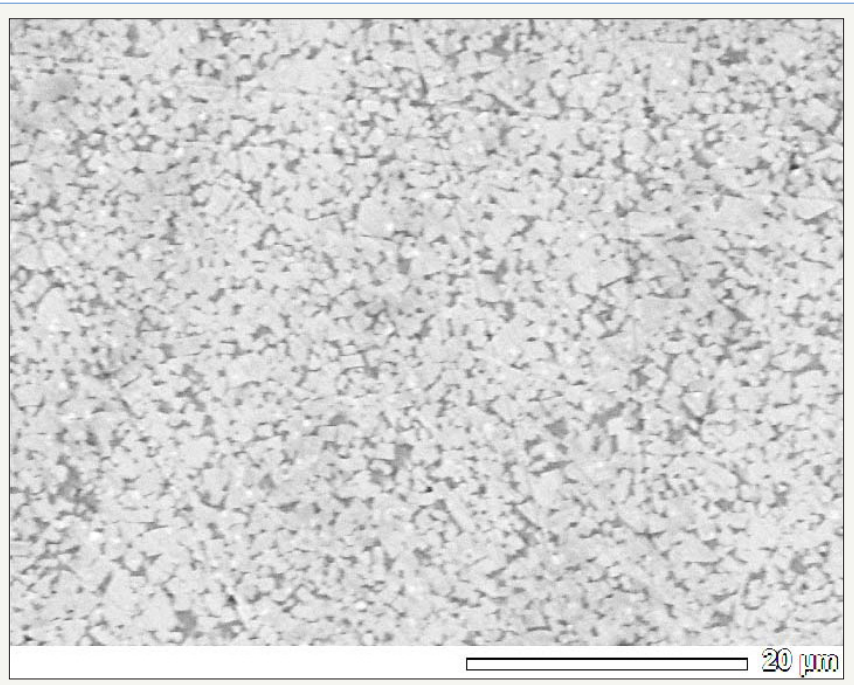

Figure 7: SEM micrographs of the WC-Co- $2 \mathrm{wt} \%$ TiC, flat surface.

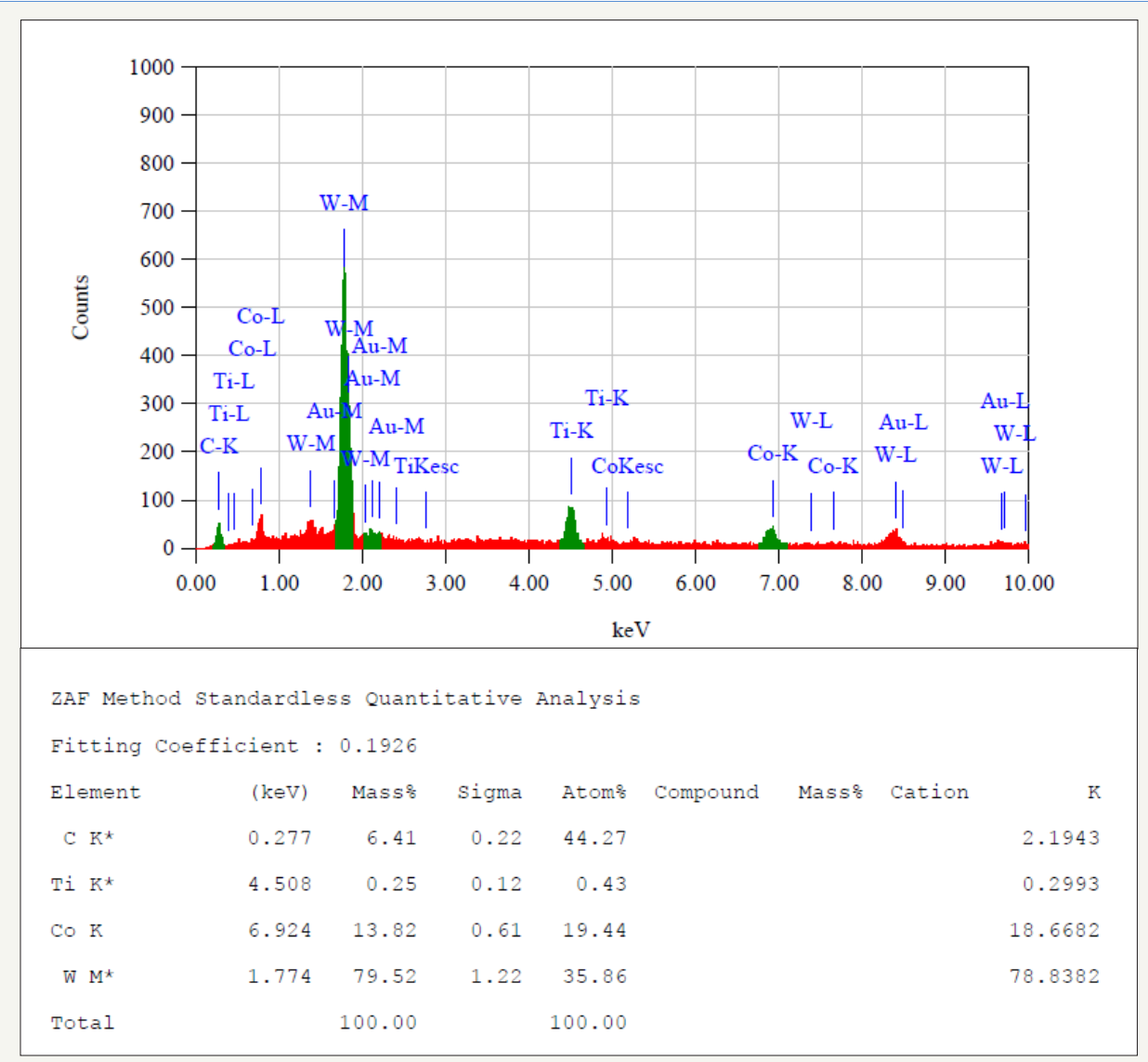

Figure 8: EDS analysis for the sample with flat surface. 


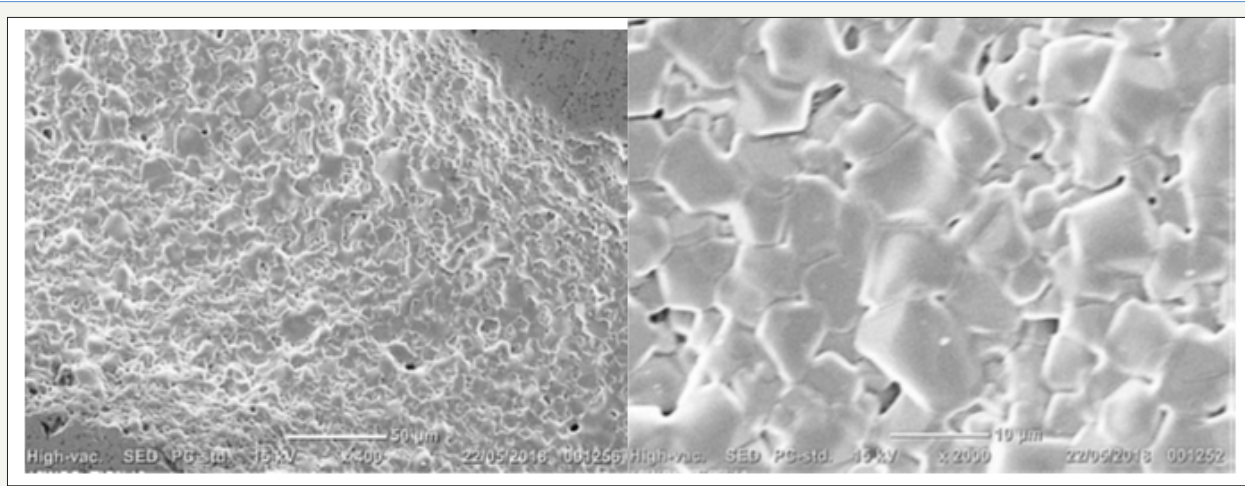

Figure 9: SEM micrographs of the WC-Co-2wt\%TiC, fractured surfaces (left) $\mathrm{x} 400$ magnification; (right) x2000 magnification.

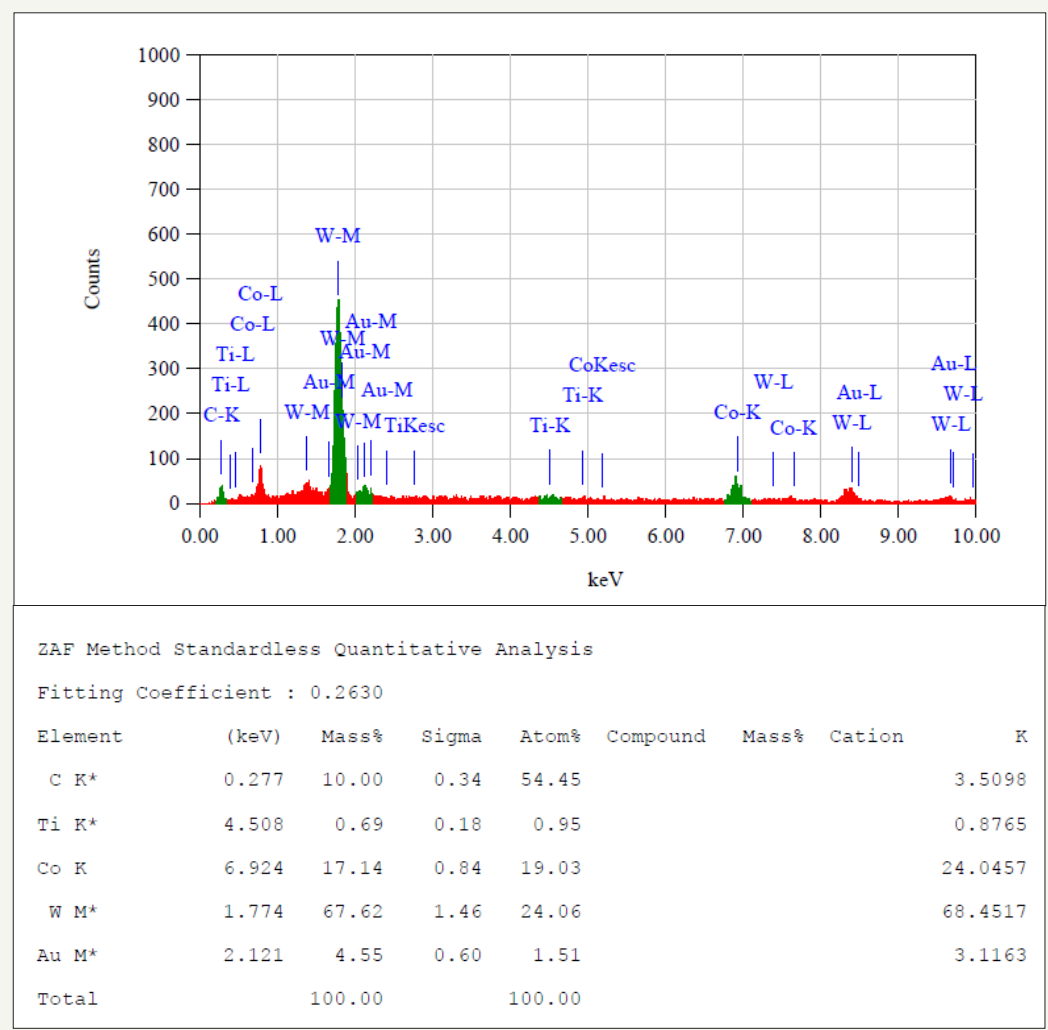

Figure 10: EDS analysis for the sample with fractured surface.

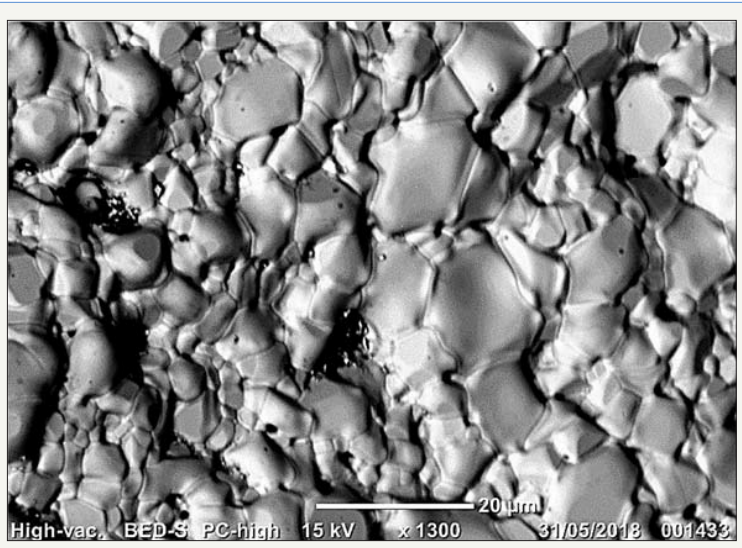

Figure 11: Backscattered electron detector, SEM micrograph of the WC-Co-2wt\%TiC fractured surfaces $\mathrm{x} 1300$ magnification.
The microstructures given in Figure 9 \& 11 show that slightly agglomerated near-nano size TiC particles uniformly covered the WC grains along the grain boundaries. Accumulation of TiC grains along the WC grain boundries indicates a role of disrupting the grain growth, meanwhile some WC grains interconnected to each other. Compared to straight WC- 13wt \% Co microstructure, addition of near-nano sized $\mathrm{TiC}$ did not affect the pore size and pore distribution. Limited number of small sized porosities can be observed in the triple junctions of interonnected grains.

Figure 11 shows a backscattered image of the microstructure using SEM's BED-S PC-high mode. A more detailed microstructure reveals quite a homogeneous distribution of slightly agglomerated TiC grains in between grown WC phases and a coherent interconnected microstructure. The WC-Co particles were covered with near-nano sized TiC grains which are embedded firmly in 
cobalt matrix. Such a coherent microstructure resulted in higher microhardness values of $1310 \mathrm{HV} 1$. In a recent work, such an increase in microhardness was reported for $1-3 w t \% \mathrm{TiC}$ addition into WC-Co grades and it was concluded that there is no correlation between the microhardness and the amount of TiC addition [1].

Further tests for cutting performance as shown in Figure 5 indicated quite higher wear resistance and a good surface quality on the machined surface with near-nano sized TiC added tools with higher microhardness values.

\section{Conclusion}

It is shown that 2 wt \% near-nano sized TiC addition into straight WC- 13 wt \% Co composition resulted in approximately $20 \%$ increase in microhardness. While there was some slight agglomeration of near-nano sized $\mathrm{TiC}$ along the grain boundaries in the final sintered microstructure, sintering process at 1460 ${ }^{\circ} \mathrm{C}$ for 60 minutes revealed distinguished grain growth and interconnection of carbide grains. Further tests for the evaluation of the wear performance, cutting tool tips prepared and mounted for the machining of a 1050 grade steel bar demonstrates almost no erosion at the cutting tool tip and a smooth and a good surface quality of the machined steel bar was achieved.

\section{Acknowledgement}

Authors thank to the Scientific Research Programme Project No. 2015-16-D1-B05 supported by the Doğuş University, İstanbul, Türkiye.

\section{Declaration of Interest Statement}

"No potential conflict of interest was reported by the authors."

\section{References}

1. Myalska H, Dybowski B, Moskal G (2017) WC-Co coatings and sinters modified with nano-sized tic microstructure - quantitative evaluation. Advances in Science and Technology Research Journal11(1): 220-231.

2. Upadhyaya GS (1997) Cemented tungsten carbides: Production, properties, and testing. Noyes Publications.

3. Dutkiewicz J, Szutkowska M, Leśniewski W, Wieliczko P, Pieczara A, et al. (2014) The effect of tic on structure and hardness of wc-co composites prepared using various consolidation methods. Composites Theory and Practice 14(2): 91-95.

4. Roxane van der Merwe (2011) Friction and sliding wear of Wc-Co inserts containing mixed carbides (TiC, $\mathrm{TaC}, \mathrm{NbC}$ ). A research report submitted to the Faculty of Engineering and the Built Environment, of the University of the Witwatersrand, in partial fulfilment of the requirements for the degree of Master of Science in Engineering. Johannesburg, South Africa.

5. Cabanas-Morena JG, Hallen-Lopez J (1998) On the solubility of phases in cemented carbides. Latin American Journal of Metallurgy and Materials 8(1-2): 48-51.

6. Constantinescu S. Properties of hard alloys sintered from metallic carbides. TEHNOMUS - New Technologies and Products in Machine Manufacturing Technologies, pp. 245-250.

7. Myalska H, Swadźba R, Rozmus R, Moskal G, Wiedermann J, et al. (2017) STEM analysis of WC-Co coatings modified by nano-sized TiC and nanosized WC addition. Surface \& Coatings Technology 318: 279-287.
Creative Commons Attribution 4.0 International License

For possible submissions Click Here

\section{Submit Article}

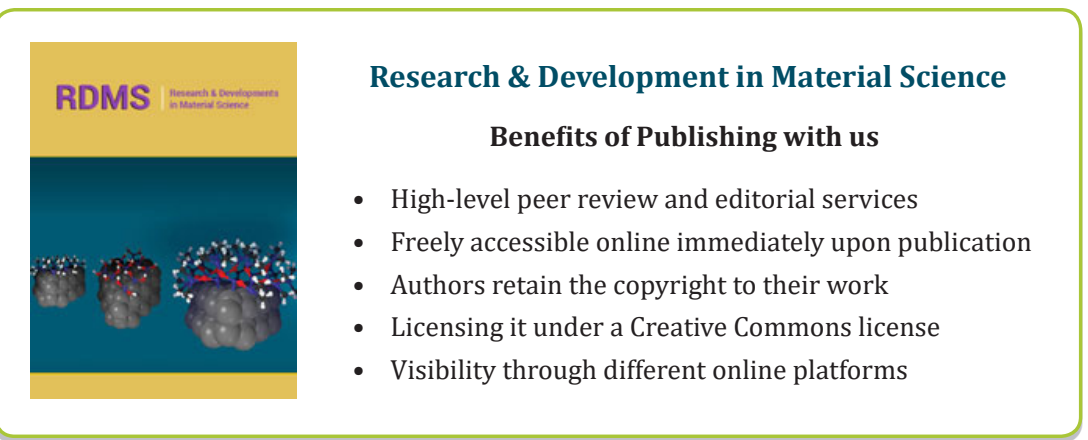

